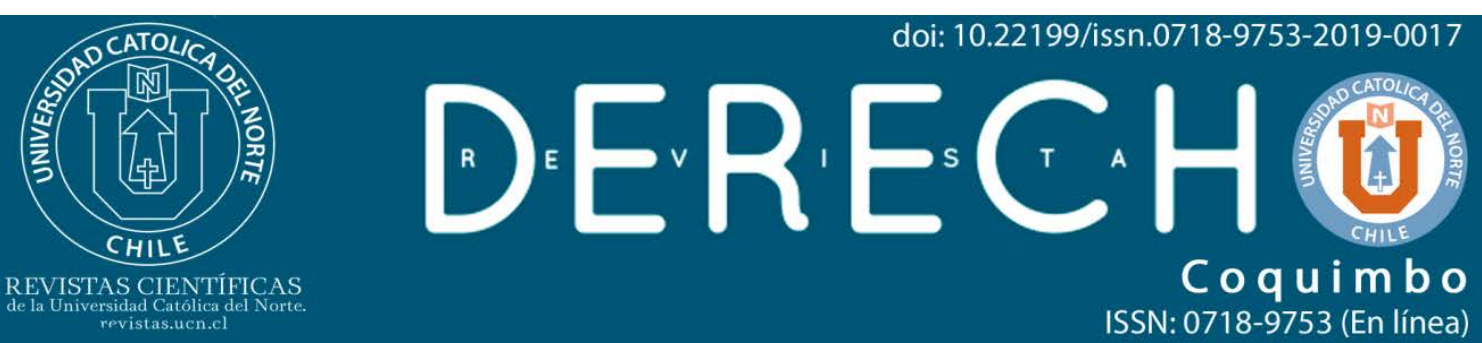

\title{
Arrendamiento de apartamentos turísticos por internet
}

\section{Lodging of tourist apartments through the internet}

\section{Carlos Amunátegui Perelló* (iD https://orcid.org/0000-0002-7063-2770}

*Pontificia Universidad Católica de Chile. Profesor. Doctor en Derecho Patrimonial, U. Pompeu Fabra

@ camunate@uc.cl

(cc) BY

\section{Resumen:}

El arriendo por corto tiempo de departamentos turísticos por Internet es un fenómeno nuevo en nuestro medio social. Al efecto, el medio empleado para su desarrollo está ocasionando una serie de consecuencias que complejizan la convivencia $y$, en muchas ocasiones, alteran el carácter de algunas zonas tradicionalmente habitacionales. El objeto de este trabajo es esclarecer las relaciones jurídicas que se desarrollan a través de tales contratos, como también explicitar los mecanismos de defensa que tienen los vecinos para objetar dicha práctica.

Palabras Clave: Airbnb; Arriendos turísticos; Ley 19.537; Consumidores.

\begin{abstract}
:
The short-term rental of tourist apartments through the Internet is a new phenomenon in our social environment. For this purpose, the means used for its development are causing a series of consequences that complicate neighbor coexistence and, in many cases, alter the character of some traditionally residential areas. The purpose of this paper is to clarify the legal relations that are developed through such contracts, as well as to explain the defense mechanisms that neighbors have to object to said practice.

Keywords: Airbnb; Touristic lodgings; Statute 19.537; Consumers.
\end{abstract}




\section{Introducción}

Siempre ha sido costumbre en Chile el arrendar viviendas amobladas para fines turísticos por temporadas cortas. Esta costumbre es antigua y se la puede detectar en múltiples cuentos y novelas de la narrativa nacional. Baste como ejemplo el célebre Papelucho, de 1947, donde en el primer libro de la serie, el personaje se va con su familia a Viña del Mar a una casa que sus padres han alquilado al efecto. Ahora bien, dicha costumbre dio lugar a una serie de regulaciones que norman la materia, si bien no siempre de una forma completa, pero usualmente de manera suficiente como para desarrollar la conducta de una manera ordenada. No obstante, desde hace unos años atrás, específicamente desde 2007 en que la compañía Airbnb nace en San Francisco, dicha costumbre se ha potenciado y desarrollado a tal nivel, que ha venido en reconvertir edificios enteros del centro de Santiago desde edificio de viviendas a lugares de alojamiento para turistas, generando tantos problemas y conflictos entre los pasajeros y los antiguos habitantes, que muchas veces estos han terminado por migrar de ellos hacia zonas sin potencial turístico donde sus vidas no se vean afectadas por el constante recambio de personas y por el ruido. Esto no es un problema específico de nuestro país, sino que se ha convertido en una tendencia general y que ha generado todo tipo de limitaciones y prohibiciones en diversas ciudades ${ }^{1}$.

Nuestro panorama jurídico se muestra incierto ante la explosión arrendamientos de corto tiempo que la aparición de compañías como Airbnb supone. La regulación aplicable no se distingue netamente, en muchos casos por desconocimiento y en otros por el discurso que rodea tales transacciones, que hacen referencia a la economía colaborativa y no a su naturaleza comercial. Esto ha llevado a que exista una sensación de desregulación. Nosotros sostenemos que el medio empleado para promover dichos arriendos y contratarlos, no tiene por qué variar la naturaleza jurídica de los mismos, y mucho menos su regulación. Si bien es cierto que el impacto social que estos nuevos medios de contratación causan es más profundo, esto plantea desafíos a nivel de la regulación territorial, de organización de la ciudad y de planeamiento urbano, más no retiran a este conjunto de contratos de su reglamentación tradicional. En dicho contexto es que, a través de este artículo, deseamos mostrar cuál es la reglamentación nacional de los arriendos de corto tiempo de departamentos amoblados, qué derechos asisten a sus usuarios y qué obligaciones mantienen sus ofertantes. Por último, y en caso que se realicen dichos arriendos en inmuebles acogidos a la Ley de Copropiedad Inmobiliaria, deseamos mostrar cuál es el de-

\footnotetext{
${ }^{1}$ Así, la ciudad de Berlín ha prohibido el alquiler de apartamentos turísticos a través de Internet, conminándose a los infractores con una multa de hasta cien mil euros, mediante la Zweckentfremdungsverbot Gestez del 12 de Diciembre de 2013.

En Nueva York, por su parte, también se aprobó una normativa similar en 2016 que prohíbe el arrendamiento turístico por Internet y lo conmina con multas de hasta siete mil quinientos dólares mediante la Senate Bill S6340A.
} 
recho de los habitantes de otras unidades y viviendas en tales edificios para oponerse al desarrollo de estas actividades.

A fin de establecer la normativa aplicable al caso, y distinguir los diversos elementos contractuales que la regulan, es menester proceder a su descripción, para luego pasar a establecer el marco jurídico que la regula y los derechos y obligaciones de las partes involucradas. Finalmente, trataremos acerca de los derechos que tienen los copropietarios en caso que tal arriendo sea de un inmueble sujeto a la Ley 19.537 (1997).

\section{Breve descripción de la operación contractual}

La operación se inicia con la inscripción de quien ofrece su casa o departamento en arriendo en la plataforma de la compañía. Para ello debe suscribir sus términos y condiciones, donde se fijan los términos generales del contrato. El oferente de arriendo pasa a llamarse "anfitrión", en la terminología de la compañía. De acuerdo a los mismos, al inscribirse, el anfitrión pasa a formar parte de una comunidad, lo cual le permite ofrecer su inmueble a través de la plataforma de la compañía. Así, la compañía señala que "Airbnb ofrece una plataforma o mercado online con tecnología para que los Huéspedes y Anfitriones entren en contacto a través de Internet y acuerden Reservas de Alojamientos directamente entre ellos" (Airbnb, inc., 2016).

La compañía declara que Airbnb no es parte de ningún acuerdo entre anfitriones y huéspedes, ni tampoco es una agencia inmobiliaria, agente o aseguradora (Airbnb, inc., 2016). En este sentido, Airbnb se autodefine como un marketplace, o lugar de mercado, donde oferentes y demandantes de alojamiento se encuentran a fin de concluir sus propias transacciones. No obstante lo anterior, la compañía se reserva el derecho de excluir de la comunidad a quien incumpla los términos generales que fijan diversas políticas respecto a los alojamientos y huéspedes, por lo que el no respetar sus políticas o los acuerdos llegados a través de la plataforma, pueden conllevar sanciones de parte de la compañía, todo esto, sin expresión de causa ni previo aviso.

A fin de publicar un anuncio, el oferente debe contestar una serie de preguntas encaminadas a establecer el tipo de inmueble ofrecido y los términos del arriendo, entre los que se incluye la política de cancelaciones. El precio es fijado en el anuncio y el oferente no puede exigir un precio distinto al establecido. La compañía señala que el único responsable de los contenidos de los anuncios publicados es el oferente, indicando que no verificará la realidad de los mismos. Explicita, además, que Airbnb no actúa como agente ni asegurador. La compañía tiene una política de cancelación de la reserva que el oferente se obliga a respetar. 
El posible arrendatario, o "huésped", en terminología de la compañía, debe también inscribirse en la plataforma, aceptando los términos y condiciones generales que fijan contractualmente sus derechos y obligaciones. Éste, de acuerdo a los anuncios exhibidos en la plataforma, puede seleccionar un alojamiento. Para ello, Airbnb entiende que el arrendatario debe concertar un contrato con el propio oferente, acuerdo respecto al cual la compañía declara no ser parte y no asume responsabilidad alguna (Airbnb, inc., 2016)². El huésped, al solicitar el alojamiento, debe pagar el importe total de la reserva a la compañía. Estos recursos no son enterados al oferente o anfitrión hasta después de realizada la estadía.

El anfitrión deberá confirmar la reserva dentro de un plazo pre-establecido y sólo entonces la compañía envía un correo de confirmación tanto al anunciante como al huésped. Si el oferente no confirma la reserva, la compañía devuelve el dinero abonado al huésped.

La compañía tiene una política de cancelaciones mediante la cual el huésped puede retractarse de su reserva con una devolución parcial o total del importe pagado. El anunciante debe adherir a esta política y el huésped, no obstante la confirmación del anunciante, puede retractarse conforme a los términos de la misma. De acuerdo a los términos generales, es el anunciante y no la compañía el responsable de respetar la reserva y sus condiciones, por lo que ésta se desliga de toda responsabilidad al respecto.

La compañía cobra tarifas por el servicio prestado, las cuales, en parte son de cargo en parte del oferente y en parte del huésped. Éstas se descuentan del monto pagado por el huésped en la reserva. Una vez confirmada la reserva, el anunciante puede cancelar la reserva, pero en tal caso se restituye el pago total realizado por el huésped y se le remiten, por parte de la compañía, otras ofertas parecidas. En este caso, la compañía puede aplicar sanciones al oferente, manteniendo bloqueados los días de la reserva, publicando una crítica en su anuncio o cobrándole una comisión de cancelación.

La compañía indica que, a su exclusivo criterio, podrá cancelar una reserva confirmada por las causas que estime convenientes, reembolsándole al huésped todo o parte de la suma pagada, todo sin que la compañía asuma ningún tipo de responsabilidades.

\footnotetext{
2 "Los Anfitriones, y no Airbnb, son los únicos responsables de respetar las Reservas confirmadas y tener disponibles los Alojamientos reservados a través del Sitio Web, la Aplicación y los Servicios. Si usted, como Huésped, decide concertar una transacción con un Anfitrión para la Reserva de un Alojamiento, acepta y entiende que estará obligado a suscribir un acuerdo con el Anfitrión y que deberá aceptar todos los términos, condiciones, reglas y restricciones asociados con dicho Alojamiento e impuestos por el Anfitrión.

Usted acepta y está de acuerdo en que usted, y no Airbnb, será responsable de cumplir las obligaciones de dichos acuerdos, que Airbnb no es parte de dichos acuerdos...".
} 
La compañía cuenta con un Centro de Resolución de Conflictos, al que somete los conflictos que puedan surgir entre los anunciantes y huéspedes. Las condiciones generales incluyen esta cláusula compromisoria y su aplicación es forzosa. No obstante, la compañía señala que no es responsable de tales arbitrajes, ni es parte de dichos acuerdos. Para los conflictos entre la compañía y los huéspedes o anfitriones, se contempla una cláusula de arbitraje forzoso ante la American Arbitration Association, de conformidad a la normativa norteamericana.

Las condiciones generales se acogen para su interpretación a las leyes del Estado de California de los Estados Unidos de Norteamérica y se confiere competencia a los tribunales de San Francisco para los procesos judiciales que se desarrollen a partir de ellas.

\section{Encuadre jurídico de la figura}

Las relaciones jurídicas establecidas a partir de una operación de arrendamiento turístico a través de la plataforma de Airbnb mantienen un esquema triangular. A este respecto, existen tres partes de la operación, la compañía, que ofrece una plataforma para llevar adelante la contratación en línea, el oferente de un inmueble amoblado para arriendos de corto tiempo, o anfitrión, y el demandante de inmuebles amoblados por corto tiempo, o huésped. Entre estas tres partes surgen diversas relaciones contractuales que configuran la operación económica y jurídica, entre la compañía y el oferente, entre la compañía y el demandante, y entre oferente y demandante. Cada una de estas relaciones tiene su propio encuadre jurídico y las relaciones que nazcan entre las partes serán diversas, por lo que las analizaremos por separado.

\subsection{Relaciones entre la compañía, el oferente y el demandante}

Las relaciones contractuales entre la compañía y el oferente de un inmueble amoblado para su arriendo por corto tiempo consisten, básicamente, en la mediación, esto es, en el esfuerzo realizado por la compañía para poner en contacto la oferta y la demanda. En este sentido, la propia compañía se define a sí misma como un marketplace, esto es, como un espacio virtual para que oferentes y demandantes de arriendos de corto tiempo se encuentren. Dicha actividad tiene una calificación jurídica precisa en nuestro ordenamiento jurídico, la de correduría. En efecto, tanto la doctrina (Eyzaguirre Echeverría, 1965, pp. 66-68; Sandoval López, 1994, pp. 226-228, Puelma Accorsi, 2002, p. 56; Puga Vial, 2005, p. 218) como la jurisprudencia (Corte Suprema, 26 de julio de 2016, 9902-2015, cons. 5; Corte de Apelaciones de Concepción, 9 de Octubre de 2015, 1255-2015, cons. 2; Corte de Apelaciones de Santiago, 23 de septiembre de 2015, 7051-2015, cons. 1; Corte Suprema, 24 de septiembre de 
2014, 1620-2014, cons. 6) ${ }^{3}$ han definido reiteradamente la actividad de mediación entre la oferta y la demanda como correduría. La correduría es un contrato bilateral y consensual (Corte de Apelaciones de Santiago, 23 de septiembre de 2015, 70512015, cons. 1), por lo que el contrato que se perfecciona entre el oferente y la compañía cuando este se inscribe en la página web, donde la compañía se obliga a ofertar mediante su plataforma el inmueble, constituye propiamente una correduría.

Ahora bien, en Chile, no obstante que el artículo 48 del Código de Comercio define a los corredores como oficiales públicos, la verdad es que no existen corredores públicos. La Comisión Revisora del Código de Comercio agregó (Eyzaguirre Echeverría, 1965, p. 66), en su artículo 80, la posibilidad que cualquier persona ejerciese la correduría privadamente, por lo que las disposiciones relativas a los corredores públicos son letra muerta en nuestro derecho. No obstante, la correduría es una actividad comercial, y como tal se encuentra tratada en el artículo 3 № 11 del mismo cuerpo legal, por lo que sus actos son de comercio, aunque medien en industrias de carácter civil (Eyzaguirre Echeverría, 1965, p. 68; Sandoval López, 1994, p. 226; Puga Vial, 2005, p. 223; Corte Suprema, 24 de Septiembre de 2014, 1620-2014, cons. 7; Corte Suprema, 19 de Noviembre de 2009, 7027-2009, cons. 4; Corte Suprema 29 de diciembre de 2008, 5304-2007, cons. 7) ${ }^{4}$. En consecuencias, las actividades de la compañía deben enmarcarse dentro del contrato de corretaje y considerarse actos de mediación entre la oferta y la demanda. En consecuencia, y por aplicación del artículo 65 del mismo cuerpo legal, la compañía no es parte de los contratos que se celebren entre oferente y huésped, no estando obligada personalmente a cumplir los contratos celebrados entre ellos, ni a asegurar su solvencia (Código de Comercio, 1865, art. 65), sino que simplemente ha de responder de la identidad de las personas que contacte y de su capacidad legal para contratar (Código de Comercio, 1865, art. 56, n. 1). En efecto, estas obligaciones se corresponden por lo declarado por la compañía en sus propios términos generales y condiciones, según vimos en el acápite precedente. No obstante, esto puede cambiar y, de hecho, deberá hacerlo en la mayor parte de las cosas, puesto que lo más corriente es que el arrendatario o "huésped", en la terminología de la compañía, suele ser un consumidor y sólo muy raramente se lo podrá calificar como prestador profesional. En este sentido, generalmente recibirá la aplicación de la Ley que establece normas sobre protección de los derechos de los consumidores:

"El proveedor que actúe como intermediario en la prestación de un servicio responderá directamente frente al consumidor por el incumplimiento de las obligaciones contractuales, sin perjuicio de su derecho a repetir contra el

\footnotetext{
${ }^{3}$ Entre las más recientes.

${ }^{4}$ No obstante, existe cierta jurisprudencia en contra de la estimación del corretaje como comercial cuando se trata de correduría de bienes raíces, véase el rol 6601-2012 de la Corte de Apelaciones de Santiago (30 de Octubre de 2013, cons. 2).
} 
prestador de los servicios o terceros que resulten responsables"(Ley 19.496, 1997, art. 43).

En definitiva, y a pesar de los términos generales de la compañía, cada vez que el arrendatario sea un consumidor (la gran mayoría de los casos), la compañía sí será responsable del cumplimiento de las obligaciones del arrendador o "anfitrión".

Debe agregarse que el contrato de correduría celebrado entre la compañía y el anfitrión, por una parte, y la compañía y el huésped, por otra, es típicamente un contrato de adhesión, donde sólo una de las partes fija las condiciones del mismo y la otra debe aceptarlo. En efecto, la compañía puede variar sus propias condiciones generales y entiende que tales cambios son vinculantes para los anunciantes y los huéspedes por el sólo hecho de permanecer en la plataforma.

Ahora bien, la calidad de comercial que los actos de correduría implican, no es necesariamente predicable para ambas partes, toda vez que los actos de comercio pueden serlo para una sola de las partes de un contrato o para ambas, de conformidad a la teoría de los actos mixtos. Por ello, no obstante que el acto es propiamente comercial para la compañía, no necesariamente lo es para el oferente de un contrato de arriendo. En este sentido, la oferta de inmuebles amoblados por corto tiempo para fines turísticos puede constituirse en un acto de comercio cuando esta oferta se encentra organizada como una empresa. Así, la Ley 20.423 (2010, art. 5, h), señala que la oferta de alojamientos turísticos puede ser comercial y, en ese caso, deberá inscribirse en el registro llevado a cabo por el Servicio Nacional de Turismo (SERNATUR) (Biblioteca del Congreso Nacional, 2010, pp. 9,172, 185) ${ }^{5}$. En general, la doctrina (Eyzaguirre Echeverría, 1965, p. 36; Sandoval López, 1994, p. 103) ha entendido que la actividad hotelera se encuentra comprendida por el art. 3 №5 del Código de Comercio, al tratar los actos que se tornan comerciales por su organización empresarial, lo cual se encuentra asentado en la jurisprudencia (Corte Suprema 28 de enero de 2013, 4038-2001; Corte de Apelaciones de Santiago 10 de Abril de 2015, 7892-2014; Corte de Apelaciones de Santiago 2 de Mayo de 2016, 217-2016). Específicamente, se ha señalado que "Un hotel constituye indudablemente un establecimiento de comercio capaz de alojar con comodidad a huéspedes o viajeros(...)“'(Corte Suprema 28 de enero de 2013, 4038-2001, cons. 14).

Al respecto, es la organización como empresarial lo que distingue la actividad hotelera de la actividad netamente civil (Corte de Apelaciones de Santiago 2 de Mayo de 2016, 217-2016, cons. 3). Así, en el caso analizado, será el conjunto de la actividad del oferente lo que nos permitirá determinar si es que se encuentra ejerciendo una actividad civil o comercial. Al respecto, el acto de ofrecer el propio departamento

\footnotetext{
${ }^{5}$ Originalmente, el proyecto enviado por el ejecutivo no incluía la voz "comercialmente" dentro del artículo. Este fue introducido mediante una indicación del ejecutivo a fin de eximir a los arrendadores ocasionales de sus propios inmuebles de esta obligación, frente a los que se encuentran organizados como empresa.
} 
durante las vacaciones cuando no se lo ocupa parece carecer de la habitualidad y organización empresarial que la actividad comercial requiere. Por contra, si el inmueble se destina específicamente al alquiler para turistas, ofreciendo un servicio de aseo, de recepción y demás características propias del hospedaje organizado como una empresa, es evidente el giro comercial. Esto tiene relevancia especialmente para la aplicación de la 19.496 (1997), toda vez que si se estima que el acto tiene un carácter mixto, por aplicación del Art. $2^{\circ}$ letra a) (Corte de Apelaciones de lquique 2 de Abril de 2013, 70-2012, cons. 5 ; Corte de Apelaciones de Concepción 12 de julio de 2013, 61-2013, cons. 3), de tal cuerpo normativo, la materia ha de regirse por las disposiciones propias del derecho de los consumidores (Momberg Uribe, 2004) ${ }^{6}$. En caso de constituirse como empresa, el oferente debería sujetarse a la normativa relativa a empresas de menor tamaño establecida al efecto en la Ley 20.416.

Por su parte, la relación de la compañía con el huésped también tiene forma de contrato de correduría, toda vez que su actividad consiste en poner al demandante de alojamientos turísticos con un oferente. No obstante, la mercantilidad de la actividad de la compañía, debe entenderse que la actividad del huésped es de carácter estrictamente civil, constituyendo él, además, un consumidor en los términos de la Ley 19.496. Al efecto, debe entenderse que el huésped (Ley 19.496, 1997, art. 1, n. 1) es un usuario final de un servicio ofertado por la compañía, la cual es una proveedora en los términos señalados por la referida ley.

Las consecuencias de la calificación jurídica de las operaciones entre la compañía y el oferente y el huésped son relevantes a varios niveles. En primer término, si la actividad de la Compañía debe regirse respecto al huésped, y eventualmente respecto al anfitrión, de conformidad a la Ley sobre Protección de los Derechos de los Consumidores, queda ésta afecta a una serie de deberes y los consumidores cuentan con un conjunto de garantías importantes que debiesen ser considerados. Sin pretender exhaustividad, podemos señalar que las condiciones generales que presenta la compañía no parecen conformarse con lo establecido en la llamada "lista negra" (De la Maza Gazmuri, 2004; De la Maza Gazmuri, 2010; Baraona González, 2014) de cláusulas abusivas fijada en el artículo 16 de la Ley 19496. Al respecto, tal disposición declara nulas las cláusulas contenidas en contratos de adhesión cuando se infringen determinados derechos y obligaciones del proveedor para con el consumidor (Baraona González, 2014 ; Hübner Guzmán, 1999).

En este sentido, parece exuberante la facultad que se arroga la compañía de resolver los contratos que por su mediación se concreten entre el anfitrión y el hués-

\footnotetext{
${ }^{6}$ En este sentido, nuestro derecho contempla una concepción amplia de la figura del consumidor. Para la situación previa a la reforma de 2004, véanse Vidal Olivares (2000) y Jara Amigo (1999). La jurisprudencia ha acogido también este criterio amplio (Corte de Apelaciones de Concepción 28 de Diciembre de 2012 203-2012, cons. 4).
} 
ped. El rol de un corredor es poner en contacto a las partes, lo cual es realizado mediante la llamada "reserva", en virtud de la cual el huésped incluso adelanta el pago de la suma total exigida por el anfitrión, más las comisiones exigidas por la compañía. A través de la confirmación del oferente, no puede sino entenderse concluido el contrato. Ante ello, ¿con qué facultades podrá la compañía simplemente rescindirlo? Sólo las partes podrán resolverlo, más evidentemente no el corredor. Aún más, la Ley 19.496 (1997) prohíbe expresamente las cláusulas que "otorguen a una de las partes la facultad de dejar sin efecto o modificar a su solo arbitrio el contrato o de suspender unilateralmente su ejecución..." (art. 1, a), por lo que tal cláusula estaría afecta a nulidad.

Otro tanto se puede señalar de las repetidas cláusulas en que la compañía declara no tener responsabilidad alguna frente a los servicios ofrecidos a través de su plataforma, que quebrantarían directamente lo preceptuado por la letra e) del mismo artículo (Ley 19.496, 1997, art. 16, e). Puede que, en definitiva, la compañía no tenga responsabilidad por un determinado incumplimiento en concreto, toda vez que en principio los corredores no son parte, ni responsables de las obligaciones nacidas de los contratos que promueven, pero declarar su irresponsabilidad a priori no es admisible dentro de nuestro sistema jurídico en las relaciones con consumidores a través de un contrato de adhesión.

Las cláusulas compromisorias que otorgan competencia a la American Arbitration Association, por su parte, no son vinculantes para los consumidores, toda vez que ellos pueden recusarla o acudir a la justicia común, a su arbitrio (Ley 19.496, 1997, art. 16, g).

En último término, la consideración de consumidor que el huésped tiene y el que anfitrión u oferente pueden presentar, implica una serie de cargas para la compañía en su mediación, las cuales no pueden ser desestimadas por unas condiciones generales propias de un contrato de adhesión, a riesgo de considerarse tales cláusulas como abusivas (Isler Soto, 2011).

\subsection{Relaciones entre el oferente y el demandante}

Las relaciones entre el oferente y el huésped se encuentran enmarcadas por las reglas relativas al contrato de arrendamiento del Código Civil. Los arrendamientos de inmuebles amoblados por corto tiempo para fines turísticos se encuentran dispersamente reglamentados en nuestro derecho. En primer término, se encuentran excluidos expresamente del ámbito de aplicación de la Ley 18.101 (1982, art. 2, no. 3) sobre arrendamiento de predios urbanos, por lo que el arrendamiento de los mismos ha de sujetarse a las reglas generales del contrato de arrendamiento de cosas dispuestas en los artículos 1916 y siguientes del Código Civil, donde se detallan las diversas obligaciones del arrendador y arrendatario. 
En segundo término, los arrendamientos de corto tiempo de inmuebles amoblados se encuentran expresamente previstos como una materia sometida en el art. 2, letra c, de la Ley 19.496, por lo que la compleja regulación relativa a derechos de consumidores les es aplicable con independencia de la calidad de comercial que tenga el arriendo para el oferente.

En tercer término, en caso que la oferta de departamentos amoblados sea comercial, la figura se encuentra regulada por la Ley del sistema institucional para el desarrollo del turismo. Al respecto, la misma define (Ley 20.423, 2010, art. 5, h) que se entiende por servicios de alojamiento turístico, a fin de establecer su ámbito de aplicación, especialmente a fin de establecer la obligación de registro de los proveedores de estos servicios en una nómina llevada al efecto por el Servicio Nacional de Turismo (SERNATUR). Al efecto, será aplicable también el Decreto 222 de 23 Junio 2011 que Aprueba el Reglamento para la Aplicación del Sistema de Clasificación, Calidad y Seguridad de los Prestadores de Servicios Turísticos (Corte de Apelaciones de Santiago 2 de Mayo de 2016, 217-2016, cons. 3 y 4). La inscripción en la nómina de proveedores turísticos es obligatoria para los oferentes comerciales y su omisión acarrea una multa (Ley 20.423, 2010, art. 50, a).

En materia tributaria, les es aplicable el Decreto Ley 825 (1974, art. 8, g), que regula la obligación de pagar Impuesto al Valor Agregado de tal tipo de arrendamiento (Corte Suprema, 28 de enero de 2013, 4038-2001, cons. 13). De esta manera, los oferentes, en cuanto se realice la pernoctación, deberán emitir boleta y proveer al pago del impuesto al valor agregado, a riesgo de cometer una infracción tributaria.

Una vez esclarecido el marco jurídico en que ha de desenvolverse la operación contractual establecida a través de la plataforma, nos queda estudiar los requisitos que ésta debe cumplir para el caso en que la unidad arrendada se encuentre afecta al régimen de copropiedad inmobiliaria establecido por la ley 19.537 y los derechos que pueden asistir a los copropietarios de tales inmuebles.

\section{La comunidad y el arrendamiento}

Lo más común en materia de arrendamientos turísticos es que la unidad arrendada pertenezca a un condominio de los regulados por la Ley de Copropiedad Inmobiliaria. Esto no es necesariamente cierto, toda vez que la unidad alquilada puede bien ser una casa independiente, pero en la gran mayoría de los casos, se trata de departamentos insertos en una comunidad de copropietarios regulada por dicha ley. Por lo demás, los conflictos que tales arrendamientos causan entre vecinos suelen producirse en este contexto. La experiencia en otros países es, por lo demás, bastante elocuente. El arriendo con fines turísticos suele transformar los edificios donde las unidades están ubicadas, desplazando a los antiguos ocupantes que terminan por 
marcharse. Esta experiencia comienza a convertirse en un lugar común en algunas áreas turísticas del centro de Santiago.

Al respecto, vale la pena recordar que la regulación de la copropiedad inmobiliaria en Chile nace con la antigua Ley 6.071 de 1937. Aunque entre los modelos de que Andrés Bello utilizó en la construcción del Código Civil sí existían disposiciones que regulasen la propiedad independiente de unidades pertenecientes a un mismo edificio ${ }^{7}$, ni el Proyecto de 1853 ni el Código Civil contemplan ninguna disposición de esta especie, tal vez por no existir precedentes en la tradición jurídica hispana (Claro Solar, 1979, p. 481) ${ }^{8}$. La situación se mantuvo así hasta que a comienzos de la década de 1930 se nombró una comisión presidida por don Arturo Alessandri Rodríguez para que redactase una nueva ley que admitiese tal forma de propiedad (Figueroa Valdés, 1996, p. 17), la cual diseñó la Ley 6.071, que por primera vez admitió esta figura en nuestro ordenamiento. La ley fue complementada por diversas normas, tanto legales como reglamentarias, hasta que en 1995 se presentó, por iniciativa del ejecutivo, un proyecto de Ley sobre Copropiedad Inmobiliaria, el cual fue finalmente promulgado y publicado en 1997.

El principio sobre que se fundamenta nuestro régimen de copropiedad inmobiliaria es, al igual que en la antigua legislación decimonónica ${ }^{9}$, que existe un dominio individual sobre cada unidad que conforma el condominio y una comunidad sobre el suelo, las escaleras y demás elementos que deban ser usados en común. El uso de las unidades se encuentra, por tanto, sujeto a diversas limitaciones que surgen del hecho de convivir en comunidad y en estrecha relación con los vecinos (Figueroa Valdés, 2002, p. 40 ${ }^{10}$. En este sentido, las limitaciones al uso y goce que puede realizar el propietario de una unidad son una aplicación específica de la interdicción de usar los bienes propios en contra del derecho ajeno, establecida en el artículo 582.

Ahora bien, en el caso de la ley de copropiedad inmobiliaria, dichas limitaciones son más estrictas, toda vez que existe entre los copropietarios un reglamento de copropiedad que puede regular de manera mucho más intensa el uso y goce las uni-

\footnotetext{
${ }^{7}$ El más famoso es el artículo 664 del Code Napoléon, que establecía la posibilidad que un mismo inmueble estuviese dividido por pisos. Esta norma inspiró diversas codificaciones y proyectos que fueron fuente de nuestro propio Código Civil, como el artículo 451 del Código de Vaud, el artículo 684 del Código Civil Sardo, el artículo 583 del Código de Nápoles y el artículo 521 de las Concordancias de García Goyena (1852, pp.449-450).

${ }^{8}$ En todo caso, muchos fueron los códigos decimonónicos que, a pesar del ejemplo francés, no admitieron la copropiedad inmobiliaria. Así, el Código de Vélez Sarsfield, de Argentina, en su artículo 2617 la prohibía expresamente, lo mismo que el BGB en su redacción original del parágrafo 1014, hoy derogado.

${ }^{9} \mathrm{Al}$ igual que el antiguo artículo 664 del Code Napoléon, derogado en 1938, nuestra legislación desde la Ley 6.071 (1937). Véase Alessandri Rodríguez, Somarriva Undurraga y Vodanovic Haklicka (1974, p. 244). Esta forma de concebir la copropiedad tiene su origen en el Derecho del Antiguo Régimen francés, en concreto en el artículo 257 de la Coutume d'Orléans, datado en 1583. (Delalande, 1704, pp. 525527; Pothier, 1845, p. 319). La Ley 19.537 (1997, art. 1) establece el mismo principio.

${ }^{10}$ En el régimen precedente a la Ley 19.537 (1997), la materia estaba regulada en términos muy similares por el artículo 51 del Decreto 880 de 1963 (Figueroa Valdés, 1996, p. 111).
}

Rev. derecho (Coquimbo, En línea) 2019, 26: e3894 
dades que conforman la copropiedad estableciendo toda clase de restricciones a dicho derecho en razón de una convivencia ordenada. Al respecto, el artículo 28 letra b) establece como uno de los objetos que puede tener el reglamento de copropiedad el imponerse limitaciones recíprocas en el ejercicio de su domino (Ley 19.537, 1997, art. 28 a y b); Figueroa Valdés, 2012, p. 279). Puesto que tal reglamento puede representar una carga importante para el propietario de la unidad, es que se inscribe en el conservador de bienes raíces como una limitación al dominio ${ }^{11}$. Se dispone:

"Los copropietarios, arrendatarios u ocupantes a cualquier título de las unidades del condominio, deberán ejercer sus derechos sin restringir ni perturbar el legítimo ejercicio de los derechos de los demás ocupantes del condominio.

Las unidades se usarán en forma ordenada y tranquila y no podrán hacerse servir para otros objetos que los establecidos en el reglamento de copropiedad o, en el silencio de éste, a aquellos que el condominio esté destinado según los planos aprobados por la Dirección de Obras Municipales. Tampoco se podrá ejecutar acto alguno que perturbe la tranquilidad de los copropietarios o comprometa la seguridad, salubridad y habitabilidad del condominio o de sus unidades, ni provocar ruidos en las horas que ordinariamente se destinan al descanso, ni almacenar en las unidades materias que puedan dañar las otras unidades del condominio o los bienes comunes" (Ley 19.537, 1997, art.32).

Es decir, el régimen de uso y goce de las unidades se encuentra limitado, en primer término, por el reglamento de copropiedad (Figueroa Velasco, 2000, p.11) ${ }^{12}$; en segundo término, por el destino que se haya asignado a la unidad según los planos aprobados por la Dirección de Obras Municipales, el que puede ser comercial o habitacional y, en tercer lugar, por el derecho de los demás copropietarios a servirse de sus unidades y no ser perturbados en su uso y goce.

Ahora bien, a fin de establecer si es que una propiedad puede ser destinada al arrendamiento turístico es menester, en primer término, revisar si este uso está o no permitido en el reglamento de copropiedad, toda vez que si los arrendamientos de

\footnotetext{
${ }^{11}$ En el derecho del Antiguo Régimen se calificaban dichas limitaciones expresamente como servidumbres, toda vez que imponían un gravamen o carga al dueño de una unidad en favor de las demás unidades, que tenían dueños diversos (Delalande, 1704, pp. 525-527).

La legislación decimonónica francesa mantuvo dicha calificación, de manera que se trató la materia entre las servidumbres en el artículo 664 del Code Napoléon. En este sentido, aunque nuestro derecho no califica como servidumbres las cargas impuestas por el reglamento de copropiedad a los dueños de las unidades, la inscripción en el registro del conservador es útil a fin de confirmar la naturaleza real de dichas cargas (toda vez que pasan a los distintos dueños junto con el bien) y de darles la necesaria publicidad.

${ }^{12}$ Respecto a la situación relativa a la Ley 6.071 de 1937 (Alessandri Rodríguez, Somarriva Undurraga y Vodanovic Haklicka, 1974, p. 249-250).
} 
este tipo se encuentran prohibidos, podrán ser impedidos por los demás copropietarios directamente o por la junta de administración en su representación (Corte de Apelaciones de Santiago 25 de Noviembre de 1996, 3626-1996, cons. 6). En segundo término, y en caso que la materia no se encuentre regulada en el reglamento de copropiedad, será menester estar al uso a que ha sido destinado el inmueble de conformidad a los planos aprobados por la Dirección de Obras Municipales. Si la unidad tiene un destino exclusivamente habitacional, evidentemente no podrá destinarse a finalidades comerciales. Como hemos visto en el acápite precedente, el arrendamiento de apartamentos amoblados por corto tiempo para fines turísticos puede tener una finalidad comercial, lo cual deberá ser calificado considerando las circunstancias propias del caso. Así, si el departamento se destina exclusivamente a alojamientos turísticos, y aún más si se adquirió con esa finalidad, o si hay empleados destinados a la recepción de pasajeros y la limpieza del departamento, la organización del arriendo parece de carácter empresarial y comercial, por lo que el arrendador no sólo quedará afecto a obligaciones tributarias y de inscripción en SERNATUR, sino que además su actividad sobrepasa los fines netamente habitacionales, para convertirse en un uso comercial. Por ello, si el destino de la unidad es habitacional, los demás copropietarios tendrán derecho a oponerse a tal actividad (Corte Suprema 13 de abril de 2012, 1669-2012).

Por último $y$, aún en caso que tal finalidad no se oponga al reglamento de copropiedad, ni sea disconforme al destino de la unidad, igualmente todos los copropietarios han de usar sus unidades en forma ordenada y tranquila, no perturbando el uso que los demás copropietarios quieran dar a las suyas emitiendo ruidos, olores, vibraciones ni otras proyecciones que puedan afectarlos. En este sentido, y por aplicación del artículo 582 del Código Civil, en el uso y goce de sus propios bienes, no deben transgredir el derecho ajeno, de conformidad a la teoría de las inmisiones (Jhering, 1863) ${ }^{13}$. En este sentido, si al destinarse la unidad al arriendo amoblado de corto tiempo el nivel de inmisiones termina por sobrepasar la normal tolerabilidad propia del uso del bien, los vecinos afectados tendrán a su disposición las diversas acciones que el derecho ofrece para paliar tal situación, entre las que se encuentran las propias de la Ley 19.537, amén de las del Derecho común, dependiendo de la entidad de la inmisión. Así, podrá ejercerse la querella de amparo, de conformidad al artículo 921 del Código Civil, si es que el ejercicio de actos posesorios sobre el bien se ve turbado o embarazado de resultas de estos arrendamientos turísticos hasta hacer difícil servirse del bien (Jiménez Salcedo, 1999, p. 54).

\footnotetext{
${ }^{13}$ La teoría de las inmisiones es una herramienta jurídica surgida a mediados del siglo XIX en Alemania por obra de Jhering, que regula el uso y goce que los propietarios pueden realizar de sus propios bienes y los límites que enfrentan en razón de las relaciones de vecindad. Tal aproximación se impuso primero en la doctrina alemana del siglo XIX y, más tarde, se consagró en el BGB en sus parágrafos 906 y 1004. Desde ahí se extendió a Italia, España y toda Europa continental. Dicha teoría parece perfectamente aplicable en nuestro medio jurídico, como creemos haber demostrado en otros trabajos anteriores. Al respecto, la doctrina recientísima ha acogido favorablemente la teoría, vea: Villarroel Matamala (2015) y Tisné Niemann (2013).
} 
Bello López (1952, p. 264 y 265), diseñó la querella de amparo para prever no sólo el despojo posesorio, sino también evitar que el ejercicio de actos en lo propio (como los arrendamientos turísticos) vacíen fácticamente el derecho del vecino. Al respecto, de conformidad a una nota incluida en el Proyecto Inédito, el modelo utilizado al redactar el título relativo a los interdictos posesorios sería Juan Sala, quien, en el apartado correspondiente indica: "No compete solamente este interdicto contra otro que pretenda la misma posesión, sino también contra aquél que sin pretenderla nos inquieta y molesta en la que tenemos..."(Sala Bañuls, 1832, p. 258).

De esta manera, si el dedicar el bien a arrendamientos turísticos importa inmisiones de tal entidad que se constituyan en una perturbación posesoria, podrá ejercerse tal querella.

Otra posibilidad para el mismo caso, en que la propiedad se vea materialmente afectada, puede caber una acción de protección, e incluso la acción negatoria de fondo.

En cuanto a las herramientas jurídicas con que cuentan los vecinos en virtud de la Ley 19.537 para oponerse a tal actividad, en primer término, existe la posibilidad que el propio comité de administración (Biblioteca del Congreso Nacional, 1997, p. 144) $)^{14}$ imponga multas a los propietarios de los departamentos que transgredan las prohibiciones del reglamento de copropiedad. Al efecto se dispone, entre las facultades del comité, "dictar normas que faciliten el buen orden y administración del condominio, como asimismo imponer las multas que estuvieren contempladas en el reglamento de copropiedad" (Ley 19.537, 1997, art. 21). Es decir, si el reglamento de propiedad prohíbe una conducta, se faculta al comité de administración a imponer multas en caso de infracción al mismo. Así, cada vez que se realice un arriendo turístico prohibido, el Comité podrá multar en sus gastos comunes al propietario infractor.

En caso que el reglamento de copropiedad no contemple una prohibición expresa, pero que se esté infringiendo el uso habitacional y no comercial del bien, el comité de administración, el administrador o cualquier persona afectada, podrán denunciar la infracción al juez de policía local a fin que éste aplique una multa de hasta 3 UTM, doblando tal monto en caso de reiteración, de conformidad a la Ley 19.537 (1997, art. 32, inc. 3).

Por último, también podrá el comité de administración tomar otras medidas tendientes a evitar tales prácticas, como negar la entrada al condominio a personas ajenas a éste.

\footnotetext{
${ }^{14}$ Durante la vigencia de la Ley 6.071 (1937), tal entidad se llamaba Junta de Vigilancia, toda vez que su rol era vigilar el actuar del administrador. Dadas las nuevas facultades que a tal entidad la Ley 19.537 ofrecía, el diputado Montes propuso el cambio de nombre a Comité de Administración, para mostrar a las claras el rol activo que tomaría bajo la vigencia de la nueva Ley.
} 


\section{Referencias Bibliográficas}

Airbnb, inc. (27 de octubre de 2016). Términos de Servicio para Usuarios Europeos. Recuperado el 5 de junio de 2017, de https://www.airbnb.es/terms

Alessandri Rodríguez, A., Somarriva Undurraga, M. y Vodanovic Haklicka, A. (1974) Derecho Civil. Tratado de los derechos reales. Santiago: Editorial jurídica de Chile.

Ana Araya Silva; con Manuel Valdés Valdés; Roberto Munita Herrera, 3626-1996 (Corte de Apelaciones de Santiago 25 de Noviembre de 1996). Recuperado de West Law CL/JUR/1437/1996.

Baraona González, J. (2014). La regulación contenida en la ley 19.496 sobre protección de los derechos de los consumidores y las reglas del código civil y comercial sobre contratos: un marco comparativo, Revista chilena de derecho, 41(2), 381-408. http://dx.doi.org/10.4067/S0718-34372014000200002.

Bello López, A. (1952). Obras completas (Vol. 3). Santiago: Nascimento.

Biblioteca del Congreso Nacional (1997). Historia de la Ley No19537 sobre Copropiedad Inmobiliaria disponible. Recuperado de https://bit.ly/2Yvn11y

Biblioteca del Congreso Nacional (2010). Historia de la Ley No20.423. Recuperado de https://bit.ly/2P60be7

Chile, Ministerio de Justicia. (2015). Código civil. Recuperado de http://bcn.cl/1uu74

Chile. Ministerio de Justicia (1865). Código de comercio. Recuperado de http://bcn.cl/1 uvv9

Claro Solar, L. (1979). Explicaciones de derecho civil chileno y comparado (Vol. 3). Santiago: Editorial jurídica de Chile.

Conejeros Solar con Mora Sotomayor, 9902-2015 (Corte Suprema 26 de julio de 2016). Recuperado de https://bit.ly/2LGKlyM

Decreto 880, de 18 de abril de 1963. Fija el texto definitivo del decreto con fuerza de Ley $\mathrm{n}^{\circ} 224$, de 1953, Ley general de construcciones y urbanización y de la Ley 6.071, Diario Oficial de la República de Chile, Santiago, 16 de mayo 1963. Recuperado de http://bcn.cl/1yfnv

Decreto Ley 825, de 27 diciembre de 1974. Ley sobre impuesto a las ventas y servicios, Diario Oficial de la República de Chile, Santiago, 31 de diciembre de 1974. Recuperado de http://bcn.cl/1uv32 
Arrendamiento de apartamentos turísticos por internet.

Delalande, J. (1704). Coutume d'Orléans (2a ed). Orléans: Jean Borde. Recuperado de http://bit.ly/38fA4Zw

De La Maza Gazmuri, I. (2004). El control de las cláusulas abusivas y la letra g). Revista chilena de derecho privado, (3), 35-68. Recuperado de https://bit.ly/2PuMleC

De La Maza Gazmuri, I. (2010). El suministro de información como técnica de protección de los consumidores: los deberes precontractuales de información. Revista de derecho (Coquimbo. En línea), 17(2), 21-52. http://dx.doi.org/10.4067/S071897532010000200002.

Eyzaguirre Echeverría, R. (1965). Derecho comercial. Parte general. Santiago: Universitaria.

Fastpro Gestion Inmobiliaria Ltda/Muñoz Barcels Rene-Charlone Herrera Macarena, 7051-2015 (Corte de Apelaciones de Santiago de 23 de septiembre de 2015). Recuperado de https://bit.ly/342AH5u

Figueroa Valdés, J. (1996). Administración de las comunidades de copropietarios. Santiago: Editorial jurídica de Chile.

Figueroa Valdés, J. (2002). La copropiedad inmobiliaria. Nuevo régimen legal. Santiago: Editorial jurídica de Chile.

Figueroa Velasco, P. (2000). Génesis, aplicación, vigencia, características y regímenes de bienes comunes. En Universidad Central de Chile (Ed.), Seminario: Copropiedad inmobiliaria. Santiago: Jurídica Cono Sur.

France (1804). Code Civil. Recuperado de https://bit.ly/2PrIWnj

García Goyena, F. (1852). Concordancias, motivos y comentarios del Código civil español (Vol. 1). Madrid: Imprenta de la Sociedad Tipográfico-Editorial. Recuperado de http://bit.ly/359ZdD2

Grupo Hotelero RQ S.A. con I. Municipalidad de Santiago, 217-2016 (Corte de Apelaciones de Santiago 2 de Mayo de 2016). Recuperado de https://bit.ly/2ry2XQd

Hübner Guzmán, A. (1999). Derecho de la contratación en la ley de protección al consumidor. En H. Corral Talciani (Ed.). Derecho del consumo y protección al consumidor (pp. 125-144). Santiago: Universidad de los Andes. Recuperado de http://bit.ly/2PGOaLh

Importadora y Exportadora Sha Sha Limitada con Banco Santander Chile, 70-2012

(Corte de Apelaciones de lquique 2 de Abril de 2013). Recuperado de

https://bit.ly/358trGp 
Industrial y Comercial Lampa Sa contra Comite de Administracion del Condominio El Taqueral de Lampa, 1669-2012 (Corte Suprema 13 de Abril de 2012). Recuperado de https://bit.ly/2sYisBc

Inmobiliaria e Inverciones Serrano Centro S.A./llustre Municipalidad de Santiago, 7892-2014 (Corte de Apelaciones de Santiago 10 de Abril de 2015). Recuperado de https://bit.ly/2RErTjD

Isler Soto, E. (2011). La relatividad de los derechos subjetivos de los consumidores. Revista chilena de derecho, 24(2), 65-89. http://dx.doi.org/10.4067/S071809502011000200003

Jara Amigo, R. (1999). Ámbito de aplicación de la ley chilena de protección al consumidor: inclusiones y exclusiones. En H. Corral Talciani (Ed.). Derecho del consumo y protección al consumidor (pp. 47-74). Santiago: Universidad de los Andes. Recuperado de http://bit.ly/2PGOaLh

Jhering, R. (1863). Zur lehre von der beschränkungen des grundeigentümers im interesse der nachbarn. Jahrbücher für die dogmatic des heutigen römischen und deutchen privatrechts, (6), 81-130. Recuperado de https://bit.ly/348NQtC

Jiménez Salcedo, M. (1999). El régimen jurídico de las relaciones de vecindad en derecho romano. Córdoba: Universidad de Córdoba.

Ley 6.071, de 11 de agosto de 1937. Dispone que los diversos pisos de un edificio y los departamentos en que se divida cada piso podrán pertenecer a distintos propietarios, Diario Oficial de la República de Chile, Santiago, 16 de agosto de 1937. Recuperado de http://bcn.cl/1vf6t

Ley 18.101, de 07 de enero 1982. Fija normas especiales sobre arrendamiento de predios urbanos, Diario Oficial de la República de Chile, Santiago, 19 de enero 1982. Recuperado de http://bcn.cl/1 uv61

Ley 19.496, de 07 de febrero de 1997. Establece normas sobre protección de los derechos de los consumidores, Diario Oficial de la República de Chile, Santiago, 07 de marzo de 1997. Recuperado de http://bcn.cl/1uvuj

Ley 19.537, de 05 de diciembre de 1997. Sobre copropiedad inmobiliaria, Diario Oficial de la República de Chile, Santiago, 16 de diciembre de 1997. Recuperado de http://bcn.cl/1 uvv7

Ley 20.423, de 04 de febrero de 2010. Del sistema institucional para el desarrollo del turismo, Diario Oficial de la República de Chile, Santiago, 12 de febrero de 2010. Recuperado de http://bcn.cl/1v3nx 
Arrendamiento de apartamentos turísticos por internet.

Marquez Tapia Ernesto / Compañia De Telecomunicaciones De Chile S.A, 7027-2009 (Corte Suprema 19 de noviembre de 2009). Recuperado de https://bit.ly/2RGvQUW

Maudier Lucero Maria Isabel con Figueroa Irribarra Alejandro y otro, 1255-2015 (Corte de Apelaciones de Concepción de 9 de Octubre de 2015). Recuperado de https://bit.ly/2E7vEWJ

Momberg Uribe, R. (2004). Ámbito de aplicación de la Ley No 19.496 sobre protección de los derechos de los consumidores. Revista de derecho (Valdivia), 17, 41-62. https://doi.org/10.4067/S0718-09502004000200002.

Ortuzar Ugarte Jose Manuel, Bottinelli Rubio Carlos con Automotores Gildemeister S.A., 1620-2014 (Corte Suprema 24 de septiembre de 2014). Recuperado de https://bit.ly/2P9J2QA

Paola Andrea Gaeta Zurita contra Claudio Leon Barroza, 61-2013 (Corte de Apelaciones de Concepción 12 de julio de 2013). Recuperado de https://bit.ly/2LINt2H

Patricio Cummins y Cia Ltda/Agricola Don Lorenzo Ltda, 6601-2012 (Corte de Apelaciones de Santiago 30 de Octubre de 2013). Recuperado de https://bit.ly/2LJETAJ

Pothier, R. (1845). Coutume d'Orléans (Vol. 1). Paris: Videcoq.

Puelma Accorsi, Á. (2002). Contratación comercial moderna. Santiago: Editorial jurídica de Chile.

Puga Vial, J. (2005). El acto de comercio. Crítica a la teoría tradicional. Santiago: Editorial jurídica de Chile.

Sala Bañuls, J. (1832). Ilustración del derecho español. Madrid: Imprenta Real.

Sandoval López, R. (1994). Derecho comercial, (Vol. 1). Santiago: Editorial jurídica de Chile.

SERNAC, Rodrigo Nahuelcura Villaman contra Falabella Retail S.A. y Gustavo Gonzalez. Dte. Civil: Brigida Angelica Mendoza Vejar. Ddo. Civil: Falabella Retail S.A., 2032012 (Corte de Apelaciones de Concepción 28 de Diciembre de 2012). https://bit.ly/2PBIFOX

Sociedad Inmobiliaria Bahía S.A. con S.I.I., 4038-2001 (Corte Suprema 28 de enero de 2003). Recuperado de https://bit.ly/38kU3Gp

Tisné Niemann, J. (2013). La teoría de las inmisiones como fundamento dogmático de la protección jurídico privada ante el ruido. Revista de derecho (Valparaíso), (40), 121181. http://dx.doi.org/10.4067/S0718-68512013000100005. 
Vidal Olivares, Á. (2000). Contratación y consumo el contrato de consumo en la ley n 19496 sobre protección a los derechos de los consumidores. Revista de derecho (Valparaíso), (21), 229 - 255. Recuperado de https://bit.ly/2YGVB9i

Viel Propiedades Ltda. con Wirth Lafuente Oscar Raul, 5304-2007 (Corte Suprema 29 de diciembre de 2008). Recuperado de https://bit.ly/2YzU6JS

Villarroel Matamala, F. (2015). Las inmisiones y la responsabilidad por daño ambiental. (Tesis de Licenciatura). Universidad Católica de la Santísima Concepción. Recuperado de https://bit.ly/347LxY3

\section{Para citar este artículo bajo Norma APA 6a ed.}

Amunátegui Perelló, C. (2019). Arrendamiento de apartamentos turísticos por internet. Revista de Derecho (Coquimbo. En línea), 26, e3894, https://doi.org/10.22199/issn.07189753-2019-0017

Copyright del articulo: @2019 Carlos Amunátegui

DOI

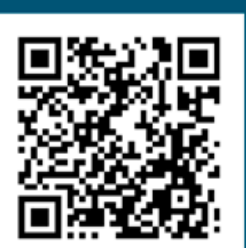

BY

Este es un artículo de acceso abierto, bajo licencia Creative Commons BY 4.0. 